\title{
Therapeutic Potential of the Natural Product Mangiferin in Metabolic Syndrome
}

\author{
Raihan H. Mirza, Nan Chi and Yuling Chi
}

Department of Medicine, Albert Einstein College of Medicine, Bronx, NY, USA

\begin{abstract}
Natural products have long been and continue to be attractive source of nutritional and pharmacological therapeutics. Interest in natural compounds as potential therapies for metabolic syndrome have recently focused on hydroxylated aromatics, such as resveratrol. Another compound of interest in this regard is mangiferin, the predominant constituent of extracts of the mango plant Mangifera indica. Mangiferin has documented antioxidant, cardioprotective and anti-inflammatory effects. Recently, pilot studies indicate bioactivity of this compound in mediating insulin sensitivity and modulating lipid metabolism. In this review we provide information on what we know about the impact of mangiferin on important biological processes involved in metabolic disorders.
\end{abstract}

Keywords: Mangiferin, metabolism, mitochondrial, oxidative stress, inflammation, hyperlipidemia, hyperglycemia, lipogenesis, lipolysis, gluconeogenesis, glycolysis.

\section{INTRODUCTION}

Metabolic syndrome is a combination of medical conditions including obesity, diabetes, nonalcoholic fatty liver disease (NAFLD), cardiovascular disease (CVD) and kidney dysfunctions. Obesity in particular is a major public health issue $[1,2]$ and it predisposes people to metabolic disorders, such as Type II diabetes, which are now prevalent in the USA and worldwide [3-5]. Metabolic syndrome involves interplay among several organs such as liver, muscle, heart, adipose tissues and pancreas, many types of cells, numerous genes and proteins, and multiple metabolic processes including gluconeogenesis, glycolysis, lipogenesis and lipolysis, all of which are regulated by complex networks and influenced by many factors such as hormones.

Treating and preventing metabolic disorders require modulation of a variety of genes, proteins, cellular signaling pathways and biological processes. Current drug development is slow, and new drugs do not appear quickly enough to halt or reverse these longterm trends in disease. This situation might be due to focus on a drug discovery strategy dominated by finding an activator or inhibitor specifically targeting one protein or gene; i.e. the higher specificity, the more desirable. The approach of high throughput screening of synthetic compounds for modulation of specific targets has not yielded a new wave of pharmacological agents to meet the demands for treating metabolic syndrome, suggesting limitations in this drug discovery

\footnotetext{
*Address correspondence to this author at the Department of Medicine, Ullmann 617, Albert Einstein College of Medicine, 1300 Morris Park Avenue, Bronx, NY 10461, USA; Tel: 718430 8913; Fax: 718430 8963;

E-mail: yuling.chi@einstein.yu.edu
}

approach [6-8]. Natural compounds, particularly those with histories of medical use, continue to represent an attractive alternative to this approach. Throughout history plants, herbs and fruits have been used as a rich source of medicine. A recent structural comparison between about 10,000 Traditional Chinese Medicine components and about 8,000 modern drugs or candidates identified 908 agent pairs that are structurally similar and 327 agent pairs that are identical in structure $[9,10]$, indicating an apparent high level of natural products or "natural product-like" representation in modern drugs. These data also suggest to us that potential medicinal applications are still available for known natural products, and the topic of this review is one such compound. The natural compound, mangeferin (MGF), has interesting potential in treatments of metabolic syndromes via modulation of multiple biological processes.

\section{CHEMICAL PROPERTIES AND BIOAVAILABILITY}

MGF is widely distributed in higher plants [11]. It is the predominant constituent of Mangifera indica extract from the plant that produces mango. In mango plant, MGF abundance is higher in the bark than in other parts of the plant [12]. In mango fruit, MGF content is in the range of $0.3 \%-1 \%(\mathrm{w} / \mathrm{w})$ in peel and less than $1 \%$ in flesh [13]. MGF is a C-glucosyl xanthone and chemically named as $C 2-\beta$-d-glucopyranosyl-1,3,6,7tetrahydroxyxanthone (Figure 1). MGF features a highly condensed aromatic ring system coupled to a glucose moiety via an unusual $\mathrm{C}-\mathrm{C}$ bond. The structure of MGF satisfies Lipinski's rules for druglike properties: molecular weight less than $500, \mathrm{LLogP}=2.73$, fewer than 5 donor functions for hydrogen bonds; and fewer than 10 acceptor functions for hydrogen bonds. These structural 
features fulfill the requisites for high bioavailability by oral administration. MGF is rapidly absorbed, for instance in rats, as MGF and its metabolites are detectable in serum and urine of rats within 1 hour after a single dose of oral administration [14, 15]. It has also been shown that MGF is able to traverse the bloodbrain barrier in gerbils [16].

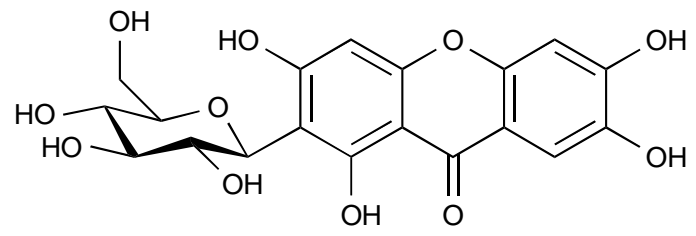

Figure 1: Chemical structure of mangiferin.

\section{BIOLOGICAL EFFECTS}

\section{Impact of MGF on Mitochondrial Oxidative Capacity, Oxidant Stress, and Inflammation}

Mitochondria are organelles essential for cellular life and normal functions. They generate cellular energy through the tricarboxylic acid (TCA) cycle and the subsequent electron transport chain (ETC). Mitochondrial dysfunction is closely associated with over 50 diseases including metabolic syndromes [1719]. MGF enhances the activities of those enzymes in the TCA cycle and raises the levels of state 3 , state 4 and ATP in mitochondrial respiration [20], an effect consistent with MGF protection of heart from isoproterenol induced myocardial infarction in rats [20]. MGF's ability to enhance mitochondrial respiration also suggests that it can potentially increase energy expenditure and possibly improve catabolism from carbohydrate or fatty acid energy stores.

The mitochondrial respiratory chain is a major source of reactive oxygen species (ROS) within the cell [21-23]. Excessive production of ROS and increased oxidative stress are participants in the development and progression of NAFLD, diabetes and its complications, and CDV [24-29]. Interestingly MGF has well established antioxidant properties, even though it enhances mitochondrial respiration. Structurally, MGF bears a catechol moiety, which enables it to form stable MGF- $\mathrm{Fe}^{2+} / \mathrm{Fe}^{3+}$ complexes, preventing Fenton-type reaction and lipid peroxidation [30]. MGF can scavenge ROS [31], thus inhibiting those processes leading to energy charge decrease and protecting against mitochondrial swelling and mitochondrial membrane potential loss [32, 33]. MGF also helps maintain the balance among the enzymes superoxide dismutase, catalase and the glutathione system [34], which have key roles in the cellular defense system against free radical damage.

ROS derived from mitochondria can act as signaltransducing molecules provoking inflammation [35]. As MGF reduces oxidant stress, presumably it can reduce inflammation. For instance MGF inhibits respiratory burst in rat neutrophils [36]. In addition, MGF suppresses the expression of prostaglandin (PG) endoperoxide synthase 2 and thereby reduces $P G_{2}$ production in rat microglia cells [37]. In primary macrophages from mice, MGF treatment significantly blunts the expression of pro-inflammatory cytokines including IL-1, IL-6, IL-12, TNF $\alpha$ and other cytokines produced by monocytes and macrophages [38]. Overnutrition triggers inflammation, which in turn contributes to the development of metabolic disorders [39]. Given the intimate relationship between the immune and metabolic systems, it is conceivable that antiinflammatory effects of MGF could be important factors in contributing to its potential ability to mitigate metabolic syndrome.

\section{MGF Inhibits Hyperlipidemia and Prevents NAFLD}

Physiological fatty acids and lipids are balanced by two processes, lipogenesis and lipolysis. Lipogenesis is catalyzed by acetyl-CoA carboxylase (ACC), fatty acid synthase (FAS), elongase, stearoyl-CoA desaturase (SCD), glycerol-3-phosphate acyltransferase (GPAT), and diglyceride acyltransferase (DGAT), which are target genes of sterol regulatory element-binding proteins (SREBPs) [39-43]. Lypolysis is catalyzed by lipase, carnitine palmitocyl transferase 1 (CPT1), long chain acyl-CoA dehydrogenase (LCAD), medium chain acyl-CoA dehydrogenase (MCAD), which are regulated by peroxisome proliferator-activated receptors (PPARs) [44].

Under pathological conditions such as over-nutrition and diabetes, imbalanced fatty acid and lipid metabolism occur, often presenting as accumulation of lipid in plasma, liver and adipose tissues. In some hyperlipidemic animal models including high fat diet (HFD) fed rats and hamsters, MGF was shown to be able to reverse elevated plasma total cholesterol, triglycerides, and LDL caused by HFD and diabetes [45-47]. In livers of HFD fed rats, MGF reduced triglyceride and free fatty acids $[46,47]$.

Mechanistically, limited literature suggests that MGF reduces ACC and DGAT2 in liver of HFD fed rats or hamsters $[46,47]$, probably by reducing SREBP-1c 
[47]. MGF also increases the ratio of phosphorylatedACC $(p-A C C) / A C C$ by inducing p-AMPK [46]. Phosphorylated ACC is the inactive form of ACC. AMPK phosphorylates ACC and inhibits ACC activity. In lipolysis, MGF increases CPT1 by inducing PPAR- $\alpha$ [47]. Although more comprehensive studies of the mechanisms of action of MGF are needed to better understand these phenomena, these preliminary reports suggest that MGF suppresses lipogenesis and stimulates lipolysis, thereby preventing HFD induced metabolic syndrome.

\section{MGF Reduces Hyperglycemia and Prevents Diabetes}

The hallmark of diabetes is hyperglycemia, a result of overload of carbohydrate, insufficient glucose disposal, and/or over production of glucose. Insufficient glucose disposal can be caused by inadequate insulin, insensitivity to insulin signaling, or impaired carbohydrate utilization mediated by enzymes in glycolysis, pyruvate dehydrogenase or lactate dehydrogenase. Over production of glucose can be caused by abnormally high levels of the enzymes in the gluconeogenesis pathway, such as glucose-6phosphatase (G6P), fructose-1,6-bisphosphatase (FBP) and glucose-6-phosphate dehydrogenase (G6PDH).

In KK-Ay diabetic mice and STZ induced diabetic rats, MGF has been reported to reduce plasma glucose and insulin levels and increase insulin sensitivity and glucose tolerance [45, 48-50]. It seems that MGF does so via several unique mechanisms. MGF is an inhibitor of glucosidase [51], which could enable it to prevent overloaded carbohydrate from being converted to glucose. For the existing glucose, MGF appears to stimulate its utilization. In rat myotubes one of the fractions of Salacia oblonga extract, with MGF as the main constituent, increases glucose transporter (GLUT)4 mediated uptake probably via activation of AMPK [52]. MGF also induces the enzymes in glycolysis such as hexokinase (HK) and pyruvate kinase (PK), and the enzymes in glycogen synthesis (glycogen, glycogen phosphorylase, glycogen synthase) [50]. Moreover, MGF has been shown to reduce $\mathrm{G} 6 \mathrm{P}$ and $\mathrm{FBP}$ and therefore inhibits gluconeogenesis [50].

\section{MGF Mitigates Cardiac Vascular Diseases}

CVD continues to be the leading cause of death worldwide [3, 4]. Abnormal mitochondrial energy metabolism and oxidative stress are critical to CVD. It has been shown that MGF can protect heart from isoproterenol induced structural alteration and functional failure in heart of rats [20], probably due to its ability to enhance mitochondrial oxidative capacity and at the same time to reduce ROS.

Hyperlipidemia and hyperglycemia are major risk factors contributing to CVD. As MGF is able to mitigate both of these factors, it is conceivable that it can prevent CVD associated with hyperlipidemia and hyperglycemia, although the antihyperlipidemia effects of MGF on CVD are likely to be complicated. As mentioned previously, MGF has the potential to not only suppress lipogenesis but also stimulate lipolysis, part of which is fatty acid oxidation. However, increased cardiac fatty acid oxidation plays a role in the development of myocardial dysfunction in diabetes [53, 54]. For instance cardiac overexpression of PPAR- $\alpha$, which stimulates $\beta$-oxidation, induces pathological cardiac changes [55]. Interestingly, in heart of Zucker diabetic fatty rats (ZDF, a genetic model of type 2 diabetes and obesity), Salacia oblonga extracts containing MGF reduced upregulated PPAR- $\alpha$ and CPT-1 and ACO mRNAs, while it enhanced hepatic expression of PPAR- $\alpha$, CPT-1 and acyl-CoA oxidase (ACO) $[53,56]$. These putative tissue specific, perhaps paradoxical, effects of MGF require further verification. Nevertheless, MGF seems to have beneficial effects on improving CVD.

\section{TOXICITY}

For any agent to be considered a potential pharmacological or nutritional therapeutics, toxicity is an issue that must be addressed. Limited toxicity studies indicate that MGF is possibly a nontoxic natural compound. In tested rats, there was no lethality or toxic reaction found at doses ranging from $25-500 \mathrm{mg} / \mathrm{kg}$ of body weight / day for a period of 30 days $[50,57]$. Rats treated with MGF at dose as high as $500 \mathrm{mg} / \mathrm{kg}$ of body weight / day for 30 days did not show respiratory distress, hair loss, restlessness, convulsions, laxative, coma, weight loss, etc. [50,57]. Although more studies are necessary to confirm the nontoxic nature of MGF, small amount is probably quite safe to humans, as MGF containing fruit, mango, has been consumed by humans and benefits human health [57-59]. The effects of MGF at higher doses in humans require further investigation.

\section{CONCLUSION}

In summary, although very limited and preliminary, the literature thus far shows that MGF interferes with 


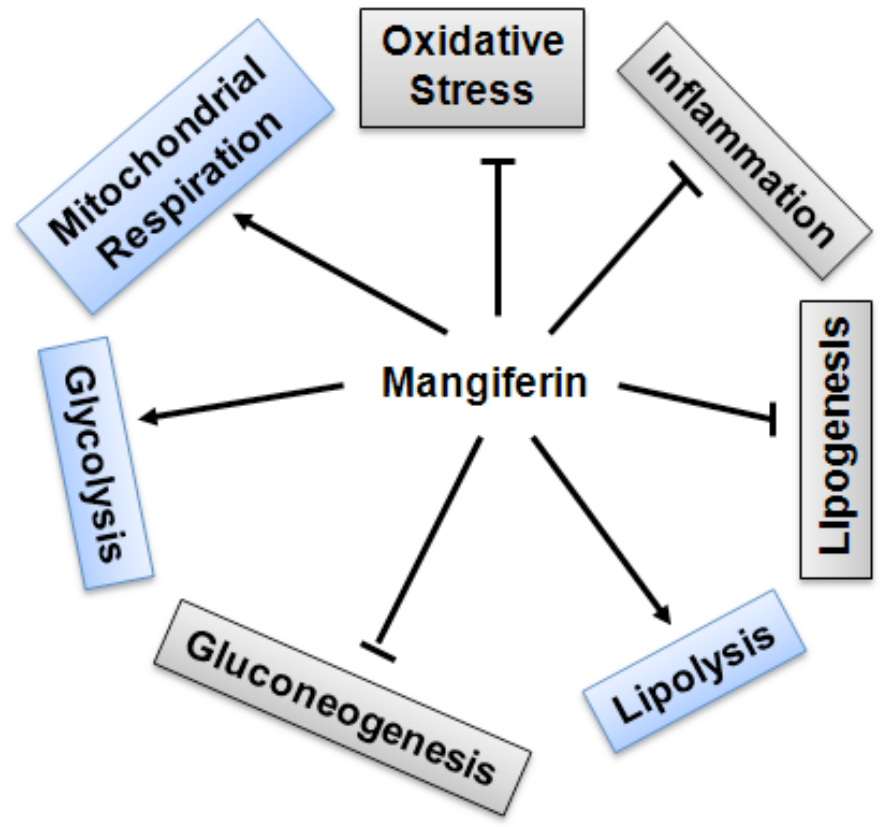

Figure 2: Predicted effects of mangiferin on biological processes involved in metabolic syndrome. MGF stimulates mitochondrial respiration, glycolysis and lipolysis. It suppresses oxidative stress, inflammation, gluconeogenesis and lipogenesis.

multiple biological processes critical to the development of metabolic syndrome (Figure 2). It stimulates mitochondrial respiration, but suppresses oxidative stress and inflammation. These are fundamental processes involved in all metabolic disorders. In addition, MGF enhances glycolysis and inhibits gluconeogenesis and thereby reduces hyperglycemia. It increases lipolysis and suppresses lipogenesis and thereby prevents hyperlipidemia. With more comprehensive and in depth studies, MGF has great potential to be developed into a nutritional/pharmacological therapeutics that could prevent and or reverse metabolic disorders by modulating multiple biological events and processes.

\section{ACKNOWLEDGEMENT}

This work was supported by the grants that Y.C. received from the American Heart Association (0735066N), from American Diabetes Association (111-JF-06), and partially from NIH/NIDDK (DK41296).

\section{REFERENCES}

[1] Flegal KM, Carroll MD, Ogden CL, Curtin LR. Prevalence and Trends in Obesity Among US Adults, 1999-2008. J Am Med Assoc 2010; 303(3): 235-41. http://dx.doi.org/10.1001/jama.2009.2014

[2] Popkin BM. The nutrition transition and obesity in the developing world. J Nutr 2001; 131(3): 871s-3s.

[3] American Heart Association. International cardiovascular disease statistics. Statistical fact sheet 2009 update. http://americanheart.org/downloadable/heart/1236204012112 INTL.pdf.
[4] American Heart Association. Heart and stroke facts: statistical update. 2010 Report. http://www.americanheart. org/downloadable/heart/1265665152970DS-3241\%20Heart Stroke Update_2010.pdf.

[5] Danaei G, Finucane MM, Lu Y, Singh GM, Cowan MJ, Paciorek CJ, et al. National, regional, and global trends in fasting plasma glucose and diabetes prevalence since 1980: systematic analysis of health examination surveys and epidemiological studies with 370 country-years and 2.7 million participants. Lancet 2011; 378(9785): 31-40. http://dx.doi.org/10.1016/S0140-6736(11)60679-X

[6] Tobinick EL. The Value of Drug Repositioning in the Current Pharmaceutical Market. Drug News Perspect 2009; 22(2): 119-25. http://dx.doi.org/10.1358/dnp.2009.22.2.1343228

[7] Grabowski H. Are the economics of pharmaceutical research and development changing?: productivity, patents and political pressures. Pharmacol Economics 2004; 22(2 Suppl 2): $15-24$. http://dx.doi.org/10.2165/00019053-200422002-00003

[8] Vernon JA. Examining the link between price regulation and pharmaceutical R\&D investment. Health Econ 2005; 14(1): 116. http://dx.doi.org/10.1002/hec.897

[9] Newman DJ, Cragg GM. Natural products as sources of new drugs over the last 25 years. J Nat Prod 2007; 70(3): 461-77. http://dx.doi.org/10.1021/np068054v

[10] Butler MS. Natural products to drugs: natural product derived compounds in clinical trials. Nat Prod Rep 2005; 22(2): 16295.

http://dx.doi.org/10.1039/b402985m

[11] Sanchez GM, Re L, Giuliani A, Nunez-Selles AJ, Davison GP, Leon-Fernandez OS. Protective effects of Mangifera indica L. extract, mangiferin and selected antioxidants against TPA-induced biomolecules oxidation and peritoneal macrophage activation in mice. Pharmacol Res 2000; 42(6): 565-73.

http://dx.doi.org/10.1006/phrs.2000.0727

[12] el Sissi HI, Saleh NA. Phenolic components of Mangifera indica. II. Planta Medica 1965; 13(3): 346-52. http://dx.doi.org/10.1055/s-0028-1100128 
[13] Daud NH, Aung CS, Hewavitharana AK, Wilkinson AS, Pierson JT, Roberts-Thomson SJ, et al. Mango extracts and the mango component mangiferin promote endothelial cell migration. J Agric Food Chem 2010; 58(8): 5181-6.

http://dx.doi.org/10.1021/jf100249s

[14] Liu H, Wu B, Pan G, He L, Li Z, Fan M, et al. Metabolism and pharmacokinetics of mangiferin in conventional rats, pseudogerm-free rats, and streptozotocin-induced diabetic rats. Drug Metab Dispos 2012; 40(11): 2109-18.

http://dx.doi.org/10.1124/dmd.112.045849

[15] Liu Y, Xu F, Zeng X, Yang L, Deng Y, Wu Z, et al. Application of a liquid chromatography/tandem mass spectrometry method to pharmacokinetic study of mangiferin in rats. J Chromatogr B Analyt Technol Biomed Life Sci 2010; 878(32): 3345-50.

http://dx.doi.org/10.1016/j.jchromb.2010.10.014

[16] Martínez Sánchez G, Candelario-Jalil E, Giuliani A, León OS, Sam S, Delgado R, et al. Mangifera indica L. extract (QF808) reduces ischaemia-induced neuronal loss and oxidative damage in the gerbil brain. Free Radic Res 2001; 35(5): 46573. http://dx.doi.org/10.1080/10715760100301481

[17] DiMauro S, Schon EA. Mitochondrial respiratory-chain diseases. New Engl J Med 2003; 348(26): 2656-68. http://dx.doi.org/10.1056/NEJMra022567

[18] Lowell BB, Shulman GI. Mitochondrial dysfunction and type 2 diabetes. Science 2005; 307(5708): 384-7. http://dx.doi.org/10.1126/science. 1104343

[19] Wallace DC. A mitochondrial paradigm of metabolic and degenerative diseases, aging, and cancer: a dawn for evolutionary medicine. Annu Rev Genet 2005; 39: 359-407. http://dx.doi.org/10.1146/annurev.genet.39.110304.095751

[20] Prabhu S, Jainu M, Sabitha KE, Devi CSS. Effect of mangiferin on mitochondrial energy production in experimentally induced myocardial infarcted rats. Vasc Pharmacol 2006; 44(6): 519-25. http://dx.doi.org/10.1016/j.vph.2006.03.012

[21] Murphy MP. How mitochondria produce reactive oxygen species. Biochem J 2009; 417(1): 1-13. http://dx.doi.org/10.1042/BJ20081386

[22] Balaban RS, Nemoto S, Finkel T. Mitochondria, oxidants, and aging. Cell 2005; 120(4): 483-95. http://dx.doi.org/10.1016/i.cell.2005.02.001

[23] Chance B, Sies $\mathrm{H}$, Boveris A. Hydroperoxide metabolism in mammalian organs. Physiol Rev 1979; 59(3): 527-605.

[24] Maritim AC, Sanders RA, Watkins JB, 3rd. Diabetes, oxidative stress, and antioxidants: a review. J Biochem Mol Toxicol 2003; 17(1): 24-38.

http://dx.doi.org/10.1002/jbt. 10058

[25] Ceriello A. Oxidative stress and glycemic regulation. Metabolism 2000; 49(2 Suppl 1): 27-9.

http://dx.doi.org/10.1016/S0026-0495(00)80082-7

[26] Baynes JW, Thorpe SR. Role of oxidative stress in diabetic complications: a new perspective on an old paradigm. Diabetes 1999; 48(1): 1-9.

http://dx.doi.org/10.2337/diabetes.48.1.1

[27] Baynes JW. Role of oxidative stress in development of complications in diabetes. Diabetes 1991; 40(4): 405-12. http://dx.doi.org/10.2337/diabetes.40.4.405

[28] Drummond GR, Selemidis S, Griendling KK, Sobey CG. Combating oxidative stress in vascular disease: NADPH oxidases as therapeutic targets. Nat Rev Drug Discov 2011; 10(6): 453-71.

http://dx.doi.org/10.1038/nrd3403

[29] Wattanapitayakul SK, Bauer JA. Oxidative pathways in cardiovascular disease: roles, mechanisms, and therapeutic implications. Pharmacol Ther 2001; 89(2): 187-206.
[30] Andreu GP, Delgado R, Velho JA, Curti C, Vercesi AE. Iron complexing activity of mangiferin, a naturally occurring glucosylxanthone, inhibits mitochondrial lipid peroxidation induced by Fe2+-citrate. Eur J Pharmacol 2005; 513(1-2): 47-55.

[31] Leiro JM, Alvarez E, Arranz JA, Siso IG, Orallo F. In vitro effects of mangiferin on superoxide concentrations and expression of the inducible nitric oxide synthase, tumour necrosis factor-alpha and transforming growth factor-beta genes. Biochem Pharmacol 2003; 65(8): 1361-71. http://dx.doi.org/10.1016/S0006-2952(03)00041-8

[32] Andreu GP, Delgado R, Velho J, Inada NM, Curti C, Vercesi AE. Mangifera indica L. extract (Vimang) inhibits Fe2+citrate-induced lipoperoxidation in isolated rat liver mitochondria. Pharmacol Res 2005; 51(5): 427-35. http://dx.doi.org/10.1016/j.phrs.2004.11.002

[33] Masibo M, He Q. Major mango polyphenols and their potential significance to human health. Compr Rev Food Sci Food Saf 2008; 7(4): 309-19. http://dx.doi.org/10.1111/j.1541-4337.2008.00047.x

[34] Rajendran P, Ekambaram G, Sakthisekaran D. Cytoprotective effect of mangiferin on benzo(a)pyreneinduced lung carcinogenesis in Swiss albino mice. Basic Clin Pharmacol 2008; 103(2): 137-42. http://dx.doi.org/10.1111/j.1742-7843.2008.00254.x

[35] Naik E, Dixit VM. Mitochondrial reactive oxygen species drive proinflammatory cytokine production. J Exp Med 2011; 208(3): 417-20.

http://dx.doi.org/10.1084/jem.20110367

[36] Andreu GL, Delgado R, Velho JA, Curti C, Vercesi AE. Mangiferin, a natural occurring glucosyl xanthone, increases susceptibility of rat liver mitochondria to calcium-induced permeability transition. Arch Biochem Biophys 2005; 439(2): 184-93.

http://dx.doi.org/10.1016/j.abb.2005.05.015

[37] Bhatia HS, Candelario-Jalil E, de Oliveira AC, Olajide OA, Martinez-Sanchez G, Fiebich BL. Mangiferin inhibits cyclooxygenase-2 expression and prostaglandin E2 production in activated rat microglial cells. Arch Biochem Biophys 2008; 477(2): 253-8. http://dx.doi.org/10.1016/j.abb.2008.06.017

[38] Leiro J, Arranz JA, Yanez M, Ubeira FM, Sanmartin ML, Orallo F. Expression profiles of genes involved in the mouse nuclear factor-kappa B signal transduction pathway are modulated by mangiferin. Int Immunopharmacol 2004; 4(6): 763-78.

http://dx.doi.org/10.1016/j.intimp.2004.03.002

[39] Hotamisligil GS. Inflammation and metabolic disorders. Nature 2006; 444(7121): 860-7. http://dx.doi.org/10.1038/nature05485

[40] Horton JD, Goldstein JL, Brown MS. SREBPs: activators of the complete program of cholesterol and fatty acid synthesis in the liver. J Clin Invest 2002; 109(9): 1125-31.

[41] Foufelle F, Ferre P. New perspectives in the regulation of hepatic glycolytic and lipogenic genes by insulin and glucose: a role for the transcription factor sterol regulatory element binding protein-1c. Biochem J 2002; 366(Pt 2): 377-91. http://dx.doi.org/10.1042/BJ20020430

[42] Horton JD, Shah NA, Warrington JA, Anderson NN, Park SW, Brown MS, et al. Combined analysis of oligonucleotide microarray data from transgenic and knockout mice identifies direct SREBP target genes. Pros Natl Acad Sci USA 2003; 100(21): 12027-32.

http://dx.doi.org/10.1073/pnas. 1534923100

[43] Choi CS, Savage DB, Kulkarni A, Yu XX, Liu ZX, Morino K, et al. Suppression of diacylglycerol acyltransferase-2 (DGAT2), but not DGAT1, with antisense oligonucleotides reverses diet-induced hepatic steatosis and insulin resistance. J Biol Chem 2007; 282(31): 22678-88. http://dx.doi.org/10.1074/jbc.M704213200 
[44] Rakhshandehroo M, Knoch B, Müller M, Kersten S. Peroxisome proliferator-activated receptor alpha target genes. PPAR Res 2010.

[45] Muruganandan S, Srinivasan K, Gupta S, Gupta PK, Lal J. Effect of mangiferin on hyperglycemia and atherogenicity in streptozotocin diabetic rats. J Ethnopharmacol 2005; 97(3): 497-501.

http://dx.doi.org/10.1016/j.jep.2004.12.010

[46] Niu Y, Li S, Na L, Feng R, Liu L, Li Y, Sun C. Mangiferin decreases plasma free fatty acids through promoting its catabolism in liver by activation of AMPK. PLoS One 2012; 7(1): e30782. http://dx.doi.org/10.1371/journal.pone.0030782

[47] Guo F, Huang C, Liao X, Wang Y, He Y, Feng R, et al. Beneficial effects of mangiferin on hyperlipidemia in high-fatfed hamsters. Mol Nutr Food Res 2011; 55(12): 1809-18. http://dx.doi.org/10.1002/mnfr.201100392

[48] Miura T, Ichiki H, Hashimoto I, Iwamoto N, Kato M, Kubo M, et al. Antidiabetic activity of a xanthone compound, mangiferin. Phytomed 2001; 8(2): 85-7. http://dx.doi.org/10.1078/0944-7113-00009

[49] Gottlieb M, Leal-Campanario R, Campos-Esparza MR, Sánchez-Gómez MV, Alberdi E, Arranz A, et al. Neuroprotection by two polyphenols following excitotoxicity and experimental ischemia. Neurobiol Dis 2006; 23(2): 37486.

http://dx.doi.org/10.1016/j.nbd.2006.03.017

[50] Sellamuthu PS, Muniappan BP, Perumal SM, Kandasamy M. Antihyperglycemic Effect of Mangiferin in Streptozotocin Induced Diabetic Rats. J Health Sci 2009; 55(2): 206-14. http://dx.doi.org/10.1248/jhs.55.206

[51] Li YH, Peng G, Li Q, Wen SP, Huang THW, Roufogalis BD, Yamahara J. Salacia oblonga improves cardiac fibrosis and inhibits postprandial hyperglycemia in obese zucker rats. Life Sci 2004; 75(14): 1735-46.

http://dx.doi.org/10.1016/j.lfs.2004.04.013

[52] GirGirón MD, Sevillano N, Salto R, Haidour A, Manzano M, Jiménez ML, et al. Salacia oblonga extract increases glucose transporter 4-mediated glucose uptake in L6 rat myotubes: role of mangiferin. Clin Nutr 2009; 28(5): 565-74.

http://dx.doi.org/10.1016/i.clnu.2009.04.018

[53] Huang TH, Yang Q, Harada M, Uberai J, Radford J, Li GQ, et al. Salacia oblonga root improves cardiac lipid metabolism in Zucker diabetic fatty rats: modulation of cardiac PPAR-alphamediated transcription of fatty acid metabolic genes. Toxicol Appl Pharmacol 2006; 210(1-2): 78-85. http://dx.doi.org/10.1016/j.taap.2005.07.020

[54] Zhou YT, Grayburn P, Karim A, Shimabukuro M, Higa M, Baetens $\mathrm{D}$, et al. Lipotoxic heart disease in obese rats: implications for human obesity. Proc Natl Acad Sci USA 2000; 97(4): 1784-9.

http://dx.doi.org/10.1073/pnas.97.4.1784

[55] Finck BN, Lehman JJ, Leone TC, Welch MJ, Bennett MJ, Kovacs $\mathrm{A}$, et al. The cardiac phenotype induced by PPARalpha overexpression mimics that caused by diabetes mellitus. J Clin Invest 2002; 109(1): 121-30.

[56] Huang TH, Peng G, Li GQ, Yamahara J, Roufogalis BD, Li Y. Salacia oblonga root improves postprandial hyperlipidemia and hepatic steatosis in Zucker diabetic fatty rats: activation of PPAR-alpha. Toxicol Appl Pharmacol 2006; 210(3): 22535.

http://dx.doi.org/10.1016/j.taap.2005.05.003

[57] Kim Y, Lounds-Singleton AJ, Talcott ST. Antioxidant phytochemical and quality changes associated with hot water immersion treatment of mangoes (Mangifera indica L.). Food Chem 2009; 115(3): 989-93.

http://dx.doi.org/10.1016/i.foodchem.2009.01.019

[58] Kim Y, Brecht JK, Talcott ST. Antioxidant phytochemical and fruit quality changes in mango (Mangifera indica L.) following hot water immersion and controlled atmosphere storage. Food Chem 2007; 105(4): 1327-34. http://dx.doi.org/10.1016/i.foodchem.2007.03.050

[59] McLendon AN, Spivey J, Woodis CB. African Mango (Irvingia gabonensis) Extract for Weight Loss: A Systematic Review. J Nutr Ther 2013; 2(1): 53-8.

Received on 15-04-2013

Accepted on 11-06-2013

Published on 30-06-2013

DOI: http://dx.doi.org/10.6000/1929-5634.2013.02.02.2

(c) 2013 Mirza et al.; Licensee Lifescience Global.

This is an open access article licensed under the terms of the Creative Commons Attribution Non-Commercial License (http://creativecommons.org/licenses/by-nc/3.0/) which permits unrestricted, non-commercial use, distribution and reproduction in any medium, provided the work is properly cited. 